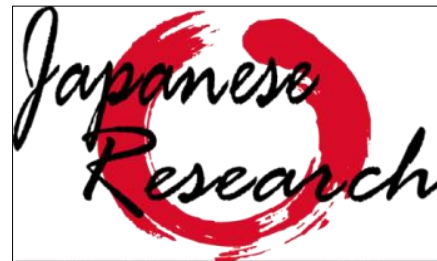

on Linguistics, Literature and Culture
Japanese Research on Linguistics, Literature, and Culture Vol. 2 No. 1 Nov. 2019, p., 1-15 ISSN Online: 2655-4836

DOI: $10.33633 /$ jr.vlil.3131

http://publikasi.dinus.ac.id/index.php/irllc/article/view/3131/1819

japanese.research@fib.dinus.ac.id

Published by Universitas Dian Nuswantoro, Semarang

\title{
Modalitas Bahasa Jepang dalam Kalimat Berpola To Omou
}

\author{
Irma Winingsih \\ Universitas Dian Nuswantoro \\ Irma.winingsih@dsn.dinus.ac.id
}

Article History: Submitted date 2019-10-9; Accepted date 2019-10-19; Published date 2019-11-25

\begin{abstract}
This writing uses a syntactic study to analyze modality to analyze the sentence structure of verb phrases to omou 'my taste/thought/ intention'. From the data the author analyzes, the modality found is the modality of ganbou's' intention', the modality of gaigen 'possibility/uncertainty' and the modality of kakugen 'full of confidence statement'. In a sentence it is possible to find two modalities, as in the data above which gives rise to two modalities, namely toui and gaigen modalities, while in other sentences it contains ganbou and gaigen modalities.
\end{abstract}

Keywords: modality, to omou, gramatical meaning

\begin{abstract}
Abstrak
Penelitian ini menganalisis modalitas dalam kalimat bahasa Jepang yang berpola $\sim$ to omou. Data yang berupa kalimat yang menggunakan pola verba to omou diidentifikasi dan kemudian dinterpretasikan dengan kajian sintaksis untuk menganalisis jenis modalitasnya. Daridata yang penulis analisis, modalitas yang ditemukan adalah modalitas ganbou 'keinginan/maksud', modalitas gaigen'kemungkinan/ ketidakpastian' dan modalitas kakugen'pernyataan penuh keyakinan'. Dari hasil analisis data juga ditemukan bahwa di dalam satu kalimat dapat terdapat dua modalitas, misalnya modalitas toui dan gaigen, dan modalitas ganbou dan gaigen.
\end{abstract}

Kata Kunci: modalitas, to omou, makna gramatikal

\section{Pendahuluan}

Sintaksis yang dalam Bahasa Jepang disebut tougoron merupakan cabang linguistik yang mengkaji unsur-unsur dan struktur pembentukan kalimat. Menurut (Verhaar (1996:111) 
sintaksis adalah cabang linguistik yang kajiannya menyangkut susunan kata-kata di dalam kalimat. Dengan kata lain dapat disimpulkan bahwa, sintaksis mengkaji struktur kata di dalam kalimat. Nitta dalam Sutedi (2011:100) menjelaskan bahwa dalam sintaksis dipelajari tataran kalimat yang mencakup jenis dan fungsinya, unsur-unsur pembentuk, serta struktur dan maknanya. Salah satu subbahasan sintaksis yang terkait dengan maknanya adalah modalitas, yang akan penulis bahas lebih lanjut di bawah ini.

Modalitas adalah cara pandang terhadap keadaan tertentu dan ungkapan tata Bahasa berdasarkan sikap penutur dalam berkomunikasi. Jadi dapat dikatakan bahwa fungsi dari modalitas adalah untuk menyatakan pandangan subjektif terhadap lawan bicara (Nitta:1991). Sementara itu semantik merupakan cabang linguistik yang membicarakan makna, baik makna kata, frasa, ungkapan maupun kalimat. Kridalaksana (2008:216) menjelaskan, semantik adalah makna yang merupakan bagian dari srtuktur bahasa dan juga struktur makna suatu wicara. Makna gramatikal merupakan salah satu objek kajian Semantik yang dalam bahasa Jepang disebut Imiron. Selanjutnya yang penulis lihat adalah pada penggunaan frasa verbal to omou, makna kalimat:

(a) Asu ame ga furu darou to omou

(b) Asu eiga wo mini ikou to omou.

Penggunaan to omou di sini secara struktur memang terlihat sama, namun jika dianalisis secara semantik, modalitasnya berbeda. Pada kalimat (a) kalimat ini adalah kalimat perkiraan/ramalan (suiryou 'kemungkinan') Penutur mengungkapkan hal yang belum pasti karena apa yang terjadi besok adalah sesuatu yang belum pasti, bisa turun hujan, bisa juga tidak turun hujan. Penggunaan modalitas to omou merupakan fitur bahasa yang mewakili ungkapan yang bermakna suiryou. Namun karena frasa verba to omou juga merupakan verba volitional yang bermakna keinginan, maksud, kemauan, seperti tertulis dalam kamus $A$ Dictionary Of Basic Japaneses Grammar (Seiishimakino dan Tsutsui dalam Simanjuntak (2010:17)) maka pada contoh kalimat (b), modalitasnya adalah intensional. Melihat perbedaan modalitas ditinjau dari makna gramatikalnya inilah penulis tertarik meneliti beberapa kalimat yang menggunakan frasa verba to omou sebagai korpus data. 


\subsection{Kajian Teoretis}

\subsubsection{Sintaksis}

Sintaksis merupakan cabang linguistik yang mengkaji unsur-unsur dan struktur pembentukan kalimat. Sintaksis ini mengkaji pengaturan dan hubungan antarkata, atau dengan satuan-satuan yang lebih besar seperti frasa, klausa atau bahkan kalimat dalam suatu bahasa (Kridalaksana, 2008:223). Sementara itu menurut (Verhaar (1996: 111) sintaksis adalah cabang linguistik yang kajiannya menyangkut susunan kata-kata di dalam kalimat. Dengan kata lain dapat disimpulkan bahwa, sintaksis mengkaji struktur kata di dalam kalimat. Dalam bahasa Jepang, sintaksis disebut tougoron. Nitta dalam Sutedi (2011:100) menjelaskan bahwa dalam sintaksis dipelajari tataran kalimat yang mencakup jenis dan fungsinya, unsur-unsur pembentuk, serta struktur dan maknanya. Salah satu subbahasan sintaksis yang terkait dengan maknanya adalah modalitas, yang akan penulis bahas lebih lanjut di bawah ini.

\subsubsection{Modalitas}

Modalitas yaitu subbahasan sintaksis yang merujuk pada peran yang memungkinkan penutur untuk mengungkapkan derajat atau tingkat komitmen atau kepercayaan terhadap suatu proposisi (Saeed, 2003:125). Sedangkan menurut Kridalaksana (1993:138) modalitas adalah klasifikasi proposisi menurut hal yang menampilkan atau dapat juga mengingkari kemungkinan atau keharusan; cara pembicara dalam menyatakan sikap terhadap suatu situasi komunikatif antarpribadi: makna kemungkinan, keharusan. Dalam bahasa Jepang, Nitta (1991:18) memberikan definisi modalitas yaitu:

Modariti to wa, genjitsu no kakawari ni okeru, hatsuwaji no hanashite no tachiba kara shita, genhyoujinou ni taisuru haaku no shikata, oyobi, sorera nit suite no hanashite no hatsuwa to dentatsuteki noudo no arikata no arawashiwake ni kakawaru bunpouteki hyougen de aru 'modalitas adalah cara pandang terhadap keadaan tertentu dan ungkapan tata bahasa berdasarkan sikap penutur dalam berkomunikasi'.

Jadi, dapat dikatakan bahwa fungsi dari modalitas adalah untuk menyatakan pandangan subjektif terhadap lawan bicara. 
Mengenai jenis-jenisnya, modalitas menurut Chaer (2002:262) dibagi menjadi empat yaitu :

1. Modalitas intensional yakni modalitas yang menyatakan keinginan, harapan, permintaan atau keharusan.

Contoh : Nenek ingin menunaikan ibadah haji.

2. Modalitas epistemik yaitu modalitas yang menyatakan kemungkinan, dan kepastian. Contoh : Kalau tidak hujan kakek pasti datang.

3. Modalitas deontik yaitu modalitas yang menyatakan keizinan atau keperkenaan. Contoh : Anda boleh tinggal di sini sampai besok.

4. Modalitas dinamik yaitu modalitas yang menyatakan kemampuan.

Sedangkan menurut Matsuoka dalam Sutedi (2011:100) menggolongkan modalitas menjadi sepuluh jenis:

1. Kakugen yaitu modalitas yang digunakan untuk menyatakan sesuatu yang dianggap pasti atas keyakinan penutur. Contoh :

(c)人間は死ぬものだ。

Ningen / ha / shinu/mono/da

Manusia/ TOP/ mati/ makhluk/ COP

'Manusia adalah makhluk yang akan mati'

2. Meirei adalah modalitas yang digunakan untuk memerintah lawan bicara agar melakukan sesuatu. Contoh :

(d) 早く行け

Hayaku / ike!

Cepat/ pergi

'Cepat pergi!'

3. Kinshikyoka yaktu modalitas yang digunakan untuk mengungkapkan larangan dan ijin melakukan suatu perbuatan. Untuk menyatakan bentuk larangan (kinshikei) digunakan verba bentuk te di ikuti waikenai atau dameda. Contoh :

(e) 明日来なくてもいいです。 Ashita / konakutemo/ii / desu.

Besok/ tidak datang pun/ tidak apa-apa/kop

'Besok tidak datang juga tidak apa-apa'. 
4. Irai yaitu modalitas yang digunakan untuk menyatakan permohonan ke orang lain agar melakukan atau tidak melakukan suatu perbuatan. Untuk ungkapan permohonan ini digunakan verba te+ kudasai, kure, kureruka, dan sebagainya. Contoh :

(f) 空を閉めてください。 Mado / wo / shimete / kudasai. Jendela/ ACC/ tutup/ tolong 'Tolong tutup jendela'.

5. Toui adalah modalitas yang menyatakan penilaian, keharusan atau memberi saran kepada seseorang. Untuk menyatakan keharusan digunakan verba bentuk futsukei+ beki, verba bentuk nakerebanai, nakutehanaranai, dan sebagainya.

Contoh :

(g) 明日七時に学校にこなければならない。 Ashita/shichi ji ni / gakkou / ni / konakereba naranai.

Besok/ pukul 07:00/ kampus/ di/ harus datang

'Besok harus datang ke kampus pukul 07:00'.

6. Ishi moushide kanyuu yaitu modalitas yang digunakan untuk mengungkapkan maksud melakukan sesuatu, menawari dan ajakan. Contoh :

(h) タクシを呼びましょうか。

Takushi / wo / yobimashouka?

Taksi/ ACC/ panggilkan

'Mari, saya panggilkan taksi?'.

7. Ganbou merupakan modalitas yang digunakan untuk menyatakan keinginan melakukan suatu perbuatan. Contoh:

(i)その映画が見たい。 Sono / eiga / ga /mitai Itu/ film/ NOM/ ingin melihat 'Saya ingin nonton film itu'.

8. Gaigen adalah modalitas yang menyatakan dugaan atau suatu kemungkinan, terhadap suatu hal karena pembicara. Di sini pembicara merasa tidak yakin dalam 
menyampaikan berita yang pernah didengarnya. Untuk menyampaikan dugaan, bisa digunakan : to omou, darou, hazuda, mitai dadan sebagainya. Contoh :

(j)たぶん、ニタさんも来るだろう。

Tabun / Nitasan / mo / kuru darou.

Mungkin/ Nita/ juga/ datang

'Mungkin, Nita juga akan datang'.

9. Setsumei yakni modalitas yang digunakan untuk menyatakan alasan saat menjelaskan suatu hal. Contoh :

(j)太郎はそのとき入院しています。つまり、彼は試験を受けなかったわけで 于。

Tarou / wa/ sono toki/ nyuuin shite imasu. / Tsumari,

Taro/ TOP/ saat ini/ sedang dirawat di rumah sakit/ dengan kata lain/ Kare/wa/shiken/wo/ ukenakatta wake/desu.

$\mathrm{Dia} / \mathrm{TOP} /$ ujian/ ACC/ tidak menggikuti/ COP

'Taro saat ini sedang dirawat di rumah sakit. Dengan kata lain, dia tidak dapat mengikuti ujian'.

10. Hikyou adalah modalitas yang digunakan untuk menyatakan perumpamaan antara dua hal atau lebih yang memiliki kesamaan mengenai suatu karakternya. Contoh :

(k) この絵は写真的で、写真のようだ。

Kono / e / wa / shashinteki / de, / shashin/ no/ you/da.

Ini/ Lukisan/ TOP/ realistis/ jadi/ foto/ GEN/ sepertinya/ kop

'Lukisan ini realistis, jadi seperti foto'.

Dari sepuluh jenis modalitas tertulis di atas, modalitas perkiraan termasuk dalam gaigen yakni modalitas yang menyatakan dugaan atau suatu kemungkinan (uncertainty) mengenai suatu hal.

\subsubsection{Semantik}

Kambartel via Pateda (1996:7) mengungkapkan bahwa semantik merupakan cabang linguistik yang mengkaji makna, baik tentang makna kata, frasa, ungkapan maupun kalimat. Pendapat lainnya datang dari Kridalaksana (2008:216) yang menjelaskan, semantik adalah makna yang merupakan bagian dari struktur bahasa dan juga struktur makna suatu tuturan. Dalam bahasa Jepang semantik disebut dengan istilah imiron. 
Sementara itu Matsuoka dan Takubo (1992:117) menyatakan bahwa mood (modalitas) merupakan kesatuan bentuk gramatikal yang mengungkapkan anggapan atau sikap penutur terhadap situasi atau lawan bicara. Pendapat lainnya dari Nitta (1991:1) yang menyatakan bahwa modalitas adalah ungkapan ekspresi gramatikal yang berkaitan dengan pengungkapan tuturan, sikap penyampaian dari pembicara, serta pemahaman terhadap realita tuturan yang dilihat dari posisi pembicara pada saat ia mengungkapkan sesuatu terkait realita. Berdasarkan hal tersebut di atas, yang dimaksud dengan modalitas adalah bentuk kata yang digunakan untuk mengekspresikan pikiran pembicara kepada lawan bicarannya dan fungsi modalitas untuk menyatakan pandangan subjektif pembicara terhadap lawan bicara.

\subsubsection{Kategori Gramatikal}

Iwabuchi via Sudjianto (2012:133) mengungkapkan bahwa kategori gramatikal sebagai aturan-aturan dalam menggunakan dan merangkai kata-kata menjadi sebuah kalimat. Makna leksikal dalam bahasa Jepang disebut jishoteki imi (辞書的意味) atau goiteki imi (語彙的意味). Pengertian makna leksikal (lexical meaning, semantic meaning, external meaning) adalah makna unsur-unsur bahasa sebagai lambang benda, peristiwa, dan lain-lain; makna leksikal ini memiliki unsur-unsur bahasa secara tersendiri, lepas dari konteks (Djajasudarma, 1999:13). Ada juga yang mengatakan bahwa makna leksikal adalah makna kamus. Misalnya kata hon (本) dan gakusei (学生) memiliki makna leksikal 'buku' dan 'pelajar'. Sedangkan makna gramatikal dalam bahasa Jepang disebut juga dengan bunpouteki imi (文法的意味). Menurut Djajasudarma makna gramatikal (bhs. Inggris - grammatical meaning, functional meaning, structural meaning, internal meaning) adalah makna yang menyangkut hubungan intra bahasa, atau makna yang muncul sebagai akibat berfungsinya sebuah kata dalam kalimat. Sedangkan menurut Sutedi dalam bahasa Jepang partikel atau joshi (助詞) dan kopula atau jodoushi (助動 詞) tidak memiliki makna leksikal, tetapi memiliki makna gramatikal, sebab baru jelas maknanya jika digunakan dalam kalimat. Misalkan partikal atau joshi [とto] secara leksikal tidak jelas artinya, namun pada saat digunakan dalam kalimat sebagai berikut:

(I) 私は先生と話します。 Watashi wa Sensei to hanashimasu. 
'Saya berbicara dengan guru'.

Verba dan adjektiva memiliki dua jenis makna tersebut, misalnya pada kata atsui (暑い) dan aruku (歩), bagian gokan : [atsu] dan [aru] bermakna leksikal 'panas' dan 'berjalan', sedangkan gobi-nya yaitu [ $\backslash i]$ dan $[<k u]$ sebagai makna gramatikalnya.

\subsubsection{Frasa verba To Omou}

Makna frasa verba to omou memiliki makna untuk menyatakan pendapat, ide, kemauan dan maksud penutur. Ketika diterjemahkan ke dalam bahasa Indonesia pandanan katanya adalah 'saya rasa/pikir/kira/bermaksud...' Yoshio mengungkapkan bahwa bentuk ini untuk mengungkapkan pendapat atau penilaian penutur kepada lawan bicaranya (2009:184). Ketika diterjemahkan ke dalam bahasa Indonesia pandanan kata frasa verba to omou ini adalah yaitu "saya pikir..." (Rohadi, 1997: 50). Bentuk yang lebih sopan (keitaikei: bahasa percakapan) adalah to omoimasu. Sedangkan bentuk lainnya yakni you to omoimasu mengungkapkan makna menyatakan maksud/rencana penutur, dan dalam bahasa Indonesia memiliki arti "bermaksud akan melakukan..." (Rohadi, 1997:55). Sementara itu bentuk to omotte iru dengan tidak menggunakan bentuk verba ikoukei merupakan pernyataan untuk mengungkapkan pendapat penutur atau orang ke III yang artinya "pikir...". Selanjutnya adalah frasa verba to omotte iru digunakan untuk mengungkapkan apa yang terpikirkan oleh penutur pada saat kejadian berlangsung. Salah satunya penutur mengetahui bahwa pendapat/penilaiannya memiliki dampak jangka panjang (Yoshio, 2009:186). Dalam bahasa Indonesia frasa verba ini diartikan "pikir..." (Rohadi, 1997:50). Sedangkan makna frasa verba to omotta digunakan untuk menyatakan apa yang telah dipikirkan penutur dalam bentuk lampau. Kemudian yang kedua adalah bahwa penutur telah memperkiraan kejadian/hal yang telah terjadi (Yoshio, 2009:186). Arti dalam bahasa Indonesia yaitu "telah/sudah..." (Sutedi, 2007: 27\&82). Sementara itu Kazuhito (2002) menyatakan:

Verb of thinking, omou, may also function as an expression of the kind of uncertainty that daro expresses. When the verb is in the suru form and when the first person subject is omitted, to omou can be replaced by darō on the whole, as in Asu wa ame ni naru to omou 'I think it is going to rain tomorrow.' However, where there is a marked modality form in the quoted clause, as in Asu wa ameni naru darō to omou 'I think it will 
probably rain tomorrow' and Asu wa eiga o mi ni ikō to omou 'I think I will go see a movie tomorrow, 'it can only express the speaker's judgment and intention, and not the meaning of uncertainty. Also, when to omou is used as an expression of uncertainty, it cannot be used in a monolog, as in (to oneself) Asu wa ame ni naru \{*to omou/darō\} naa 'I think it'll rain tomorrow'). This shows that to omou is an expression which objectivizes one's own thought content and communicates it to the listener expressions.

Permasalahan dari penelitian ini adalah bagaimana makna gramatikal dari penggunaan frasa verba to omou dan bagaimana modalitasnya. Tujuannya adalah untuk mencari tahu dan mendeskripsikan makna gramatikal dari penggunaan frasa verba to omou dan bagaimana modalitasnya.

\section{Metode Penelitian}

Penelitian ini merupakan penelitian kualitatif dengan satuan analisis data berupa kalimat yang menggunakan frasa verba to omou berikut konjugasinya. Data merupakan kumpulan kalimat yang menggunakan frasa verba to omou yang penulis ambil dari https://japanesetest4you.com/flashcard/learn-jlpt-n4-vocabulary-思う-omou/. Analisis berupa analisis studi pustaka yang kemudian diinterpretasikan secara Semantik dengan teori Yoshio untuk menganalisis makna gramatikalnya, yang kemudian dilanjutkan secara Sintaksis dengan teori modalitas dari Matsuoka untuk mengetahui modalitasnya. Hasil analisis kemudian dideskripsikan menjadi tulisan dalam artikel ini.

\section{Hasil dan Pembahasan}

Dari 26 data yang penulis temukan, penulis menganalisis dan mengkategorisasikan menjadi 3 yakni yang bermakna ishikei (keinginan) ada 7 data, kakugen (fakta) 1 data, suiryou (kemungkinan) 18 data

Yang bermakna ishikei:

1.私は、生活を一変したいと思ってる。

Watashi wa, seikatsu o ippen shitai to omotteru

'Saya ingin membuka lembaran baru sepenuhnya' Analisis : 
Pada kalimat di atas verba suru mengalami konjugasi menjadi bentuk ingin tai menjadi shitai. Bentuk frasa verba to omou berkonjugasi menjadi to omotteru yang merupakan casual speech (bahasa informal) dari to omotte iru yang merupakan konjugasi dari to omou yang berarti 'sedang dilakukan'. Dengan menggunakan verba shitai + to omotte iru, maka makna yang muncul adalah berkeinginan. Pada analisis ini modalitasnya tertulis jelas pada bentuk verba shitai to omotteru. Subjek yaitu watashi'saya' menyatakan keinginan untuk membuka lembaran baru dalam hidupnya. Ini mewakili modalitas ganbou dengan wujud keinginan/maksud.

2.私は常々、見かけだけで人を判断したくないと思ってるの

Watashi wa tsunezune, mikake dake de hito o handan shitakunai to omotteru no.

'Saya selalu tidak ingin menilai seseorang hanya dari penampilannya'

Analisis:

Pada kalimat ini digunakan bentuk hiteikei'negasi'dari konjugasi verba tai yaitu kata handan shitakunai'tidak ingin menilai'. Verba suru'melakukan/mengerjakan' mengalami konjugasi shitai 'ingin melakukan/mengerjakan'dan kemudian dinegasikan menjadi shitakunai'tidak ingin melakukan/mengerjakan'. Omotteru adalah bentuk casual speech dari omotte iru yang merupakan aspek'sedang terjadi' dari frasa verba to omou. Meskipun berupa bentuk negasi, namun tetap bermodalitas keinginan karena maknanya adalah penutur bermaksud/berkeinginan untuk tidak melakukan sesuatu, yakni menilai seseorang hanya dari penampilan luarnya saja. Mengapa demikian, karena pola kalimatnya menggunakan konjugasi verba shitai yang bentuk negasinya adalah shitakunai. Menurut Matsuoka konjugasi verba $\sim$ tai mewakili perwujudan modalitas ganbou.

3. 私は野原にいって、星のしたに野宿しようと思いました。 Watashi wa nohara ni itte, hoshi no shita ni nojuku shiyou to omoimashita.

'Aku pergi ke ladang, berniat tidur di udara terbuka, di bawah bintang-bintang.'

Analisis:

Pada data di atas, verba suru'melakukan/mengerjakan' mengalami perubahan konjugasi bentuk ikoukei dan berubah menjadi shiyou. Pola kalimat verba ikoukei + to omou merupakan pola kalimat yang menyatakan keinginan/ maksud. Watashi sebagai subjek menyatakan keinginan 
untuk pergi ke ladang (iku'pergi' menjadi itte (konjugasi bentuk $\sim$ te)). Di sini frasa verba $\sim$ to

omou bentuknya lampau menjadi omoimashita (bentuk halus dari omotta), artinya bahwa perbuatan berpikir/bermaksud/berkeinginan itu sudah terjadi. Dengan menggunakan pola frasa verba konjugasi ikoukei shiyou to omoimashita, kalimat ini memiliki modalitas ganbou, sama dengan dua data sebelumnya.

Yang bermakna suiryou:

1.わたしは、身振りがとても重要だと思います

Watashi wa, miburi ga totemo juuyou da to omoimasu

'Menurutku bahasa tubuh itu sangat, sangat penting'

Analisis:

Subjek yaitu watashi menuturkan bahwa bahasa tubuh (miburi) adalah penting (juuyou). Jika kalimat ini diakhiri dengan no desu/no da, maka makna gramatikalnya menunjukkan suatu fakta yang diyakini oleh penutur tanpa keraguan. Partikel no fungsinya untuk mempertegas tuturan, sedangkan desu/da merupakan kopula yang fungsinya mengakhiri kalimat pernyataan yang sopan. Namun dengan menggunakan to omoimasu di akhir kalimat, penutur berusaha untuk membatasi pendapatnya sebagai hanya untuknya sendiri. Dengan menggunakan frasa verba ini, penutur mengaburkan keobjektifan fakta yang dia nyatakan. Atau dengan kata lain dikatakan penutur belum yakin 100 \% bahwa pendapatnya itu diterima oleh petutur sebagai sesuatu yang benar. Ada kemungkinan bahwa orang lain berpendapat beda, bahwa bahasa tubuh tidak terlalu penting misalnya. Perhatikan contoh kalimat di bawah ini:

(m) わたしは、身振りがとても重要だと思います(modalitas gaigen)

Watashi wa, miburi ga totemo juuyou da to omoimasu.

'Menurutku bahasa tubuh itu teramat penting'

(n) 身振りがとても重要だ/です. (modalitas Kakugen)

Miburi ga totemo juuyou da/desu

'Bahasa tubuh itu penting'

Pada contoh kalimat (n), penutur lebih yakin terhadap apa yang diucapkannya. Penutur menyatakan keobjektifan dari pendapatnya sebagai pendapat umum yang sudah diakui, dengan menggunakan bentuk $d a / d e s u$ yang merupakan kopula untuk mengakhiri kalimat pernyataan 
bentuk sopan. Sedangkan pada contoh $(\mathrm{m})$ maknanya berbeda karena frasa verba to omou'menurutku, saya rasa, saya pikir' membuat sebuah fakta menjadi lebih subjektif. modalitas yang muncul di sini adalah gaigen, karena penutur menggunakan frasa verba $\sim$ to omou, berarti penutur mengubah suatu fakta menjadi hal pribadi yang belum pasti kebenarannya.

2.それで、わたし、いままでに会ったこともない奇妙な人たちだと思った。 Sore de, watashi, ima made ni atta koto mo nai kimyou na hitotachi da to omotta.

'Saya benar-benar berpikir mereka adalah orang-orang paling aneh yang pernah saya temui'

Analisis:

Subjek pada kalimat ini adalah watashi'saya'. Subjek menggunakan frasa verba to omotta yang merupakan bentuk lampau formal (joutai) dari to omou di akhir kalimat. Bentuk lampau merepresentasikan perbuatan yang sudah dilakukan sehingga dapat diartikan bahwa penutur telah memikirkan mengenai hal itu sebelumnya, dan sekarang ada kemungkinan pemikiran tersebut sudah berubah/belum berubah sama sekali. Ima made ni atta koto mo nai kimyou na hitotachi menyatakan bahwa penutur sampai sekarang belum pernah bertemu dengan orangorang yang telah/pernah dianggapnya aneh tersebut. Pendapat subjek bahwa orang-orang (tersebut) adalah aneh merupakan pendapat pribadi dari subjek, watashi. Karenanya penutur menggunakan frasa verba to omotta untuk menunjukkan bahwa pendapatnya itu bisa salah, bisa juga benar dan disetujui semua orang. Penggunaan frasa verba $\sim$ to omotta membuat tuturan menjadi tidak pasti dan tidak mutlak. Ini merupakan representasi dari modalitas gaigen.

Yang bermodalitas Kakugen:

1.誰もが製造業が危機にひんしていると思っています

Daremo ga seizougyou ga kiki ni hinshite iru to omotte imasu

'Semua orang berpikir manufaktur berada dalam krisis'

Analisis:

Subjek pada kalimat ini adalah daremo'siapapun'. Dapat dikatakan bahwa subjek adalah orang ke III. Hinshite iru adalah aspek yang bermakna sedang terjadi dari verba hinsuru'miskin'. Penutur menyatakan fakta bahwa semua orang sedang berpikir hal yang sama mengenai kondisi krisis (kiki) yang menimbulkan kemiskinan (hinshite iru). Frasa verba to omotte imasu 
adalah bentuk aspek $\sim$ te iru dari $\sim$ to omou. Lagipula pada data di atas, bentuk $\sim$ te iru merupakan bentuk verba yang digunakan untuk orang ke III. Daremo ga seizougyou ga kiki ni hinshite iru adalah fakta yang dipikirkan oleh siapapun, sedangkan kalimat lengkap di atas diucapkan oleh penutur untuk mengungkapkan fakta yang terjadi. Penandanya adalah bentuk futsuukei sebelum frasa verba to omotte imasu. Tidak ada wujud modalitas keinginan yang diungkapkan di sini, melainkan hanya penyampaian fakta dari pendapat siapapun. modalitas yang muncul adalah Kakugen karena penutur menyampaikan suatu fakta yang objektif bahwa siapapun sedang memikirkan krisis tersebut.

Yang bermakna ambigu :

1.わたしは何も騒ぐ必要はないと思う。

Watashi wa nanimo sawagu hitsuyou wa nai to omou.

'Saya pikir tidak ada hal yang mesti diributkan'

Analisis:

Pada data ini terdapat 2 modalitas yakni modalitas toui yang menyatakan ketidakpentingan/ketidakperluan dan modalitas ganbou yang menyatakan keinginan/ maksud penutur. Menurut Miyazaki (2002) modalitas toui dapat diklasifikasikan lagi, salah satunya menjadi penilaian terhadap sesuatu hal, dan menyatakan ketidakpentingan/ketidakperluan hal tersebut. Hitsuyou ha nai merupakan salah satu fitur bahasa yang mempresentasikan modalitas ini. Hitsuyou ha nai merupakan penilaian terhadap perlu atau tidak perlunya meributkan sesuatu hal (nanimo sawagu). Analisis lainnya menyatakan bahwa kalimat ini mengandung modalitas gaigen. Mengapa demikian, pada kalimat ini mengandung ungkapan pendapat, bahwa tidak ada hal yang harus diributkan. Watashi wa nanimo sawagu hitsuyou wa nai merupakan proposisi dari apa yang dipikirkan penutur sebagai sebuah pendapat. Penutur berpendapat dan karena itu bersifat subjektif, maka penutur menggunakan frasa verba $\sim$ to omou. Faktanya, perlu atau tidaknya hal tersebut diributkan, benar-benar menjadi hal yang tidak pasti. Inilah yang merepresentasikan modalitas gaigen pada kalimat ini.

2. 買い物が 1 時間ぐらいかかると思う。

Kaimono ga ichi jikan gurai kakaru to omou.

'Saya rasa (saya) akan belanja selama 1 jam'

Analisis:

13 | P a g e 
Data di atas mengandung 2 modalitas yakni modalitas gaigen dan modalitas ganbou. Analisis makna gramatikalnya adalah sebagai berikut; subjek pada tuturan ini adalah penutur. Penutur menyatakan keinginannya untuk berbelanja selama kurang lebih 1 jam. Hal ini terungkap dari pola kalimat verba futsuukei + to omou. Kaimono ga ichijikan kakaru to omou bermakna keinginan yang belum dilaksanakan, atau baru akan dilakukan. Namun jika dinyatakan mengandung modalitas gaigen adalah jika dianalisis secara gramatikal sebagai berikut. Proposisi kaimono ga ichi jikan kakaru'belanja memakan waktu sekitar 1 jam' adalah pendapat dari penutur. Karena ini merupakan pendapat yang dapat saja berbeda dengan pendapat orang lain, penutur kemudian menambahkan frasa verba to omou. Orang lain mungkin saja berpendapat bahwa untuk berbelanja (di tempat yang dirujuk penutur), akan memakan lebih dari 1 jam atau mungkin juga kurang dari 1 jam. Dengan menggunakan frasa verba ini, penutur membuat tuturannya bersifat subjektif dan tidak pasti (gaigen).

\section{Simpulan}

Dari data yang penulis analisis, modalitas yang ditemukan adalah modalitas ganbou 'keinginan/maksud', modalitas gaigen 'kemungkinan/ketidakpastian' dan modalitas

Kakugen'pernyataan penuh keyakinan'. Untuk dapat menemukan modalitas dari sebuah kalimat, perlu dilakukan analisis makna gramatikal. Dalam suatu kalimat memungkinan ditemukannya dua modalitas, seperti pada data di atas yang memunculkan dua modalitas, yakni modalitas toui dan gaigen, sedangkan pada kalimat yang lain mengandung modalitas ganbou dan gaigen.

\section{Referensi}

Chaer, Abdul. (2002). Pengantar Semantik Bahasa Indonesia. Jakarta: Rineka Cipta.

Dahidi, A. dan Sudjianto.2012. Pengantar Linguistik Bahasa Jepang. Jakarta: Kesaint Blanc.

Djajasudarma, T. Fatimah. (1999). Semantik 2, Pemahaman Ilmu Makna. Bandung: PT Refika Aditama.

Iwabuchi, Tadasu. (1989). Nihon Bunpoo Yoogo Jiten. Tokyou : Sanseido

Kazuhito, Miyazaki. (2002) 'Ninshiki no modaritii' (Epistemic Modality) in Miyazaki, Kazuhito et al., Modaritii "Modality." Japan: Kuroshio Shuppan.

Kridalaksana, Harimurti. (2008). Kamus Linguistik. Jakarta: Gramedia Pustaka Utama 
Matsuoka, Takashi dan Takubo Yukinori. (1993). Kiso Nihongo Bunpou. Tokyo: Kuroshio Shuppan.

Nitta, Yosshio. (2003). Gendai Nihongo Bunpo Sensho 4 Modariti. Tokyo: Kuroshio Shuppan.

Nitta, Yoshio.(2009). 現代日本語文法 4. Edisi 1. Japan: Kodansha.

Pateda, Mansoer. (1996). Semantik Leksikal. Jakarta : Rineka

Riza, Miftah. (2016). Grammar Bahasa Jepang : to omou, you to omou ( と思う/ようと思

う). [Forum Online]. Diakses pada tanggal 17 Oktober 2019 dari http://bahasajepangbersama.blogspot.co.id/2014/08/grammar-bahasa-jepang-to omou-you-to-omou.html.

Rohadi. (1997). Bentuk Ungkapan Kata Kerja yang Bervariasi Jilid 3. Jakarta: Kesaint Blank.

Saeed, John I. (2003) Semantics, Beijing: Blackpaint.

Seiishi, Makino dan Tsutsui, Michio. (1989) A Dictionary Of Basic Japaneses Grammar, Japan: The Japan Times

Sutedi, Dedi. (2007a). Nihongo No Bunpou Tata Bahasa Jepang Tingkat Dasar (Edisi Revisi). Bandung: Humaniora Utama Press.

Sutedi, Dedi. (2003). Dasar-dasar Linguistik Bahasa Jepang. Bandung: Humaniora Utama Press (UHP).

https://japanesetest4you.com/flashcard/learn-jlpt-n4-vocabulary-思う-omou 